\title{
A cross-sectional study of early identification of postpartum depression: Implications for primary care providers from The Ontario Mother \& Infant Survey Susan Watt*1,2, Wendy Sword ${ }^{2,3}$, Paul Krueger ${ }^{4,5}$ and Debbie Sheehan $3,6,7$
}

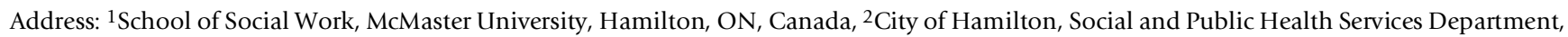
Public Health Research, Education and Development Program, Hamilton, ON, Canada, ${ }^{3}$ School of Nursing, Faculty of Health Sciences, McMaster University, Hamilton, ON, Canada, ${ }^{4}$ Department of Clinical Epidemiology and Biostatistics, McMaster University, Hamilton, ON, Canada, 5 St. Joseph's Health Care System Research Network, 97 Mount Pleasant St., Brantford, ON, Canada, ${ }^{6}$ City of Hamilton, Social and Public Health Services Department, Environmental Health and Infectious Diseases Branch, Hamilton, ON, Canada and ${ }^{7}$ Department of Family Medicine, Faculty of Health Sciences, McMaster University, Hamilton, ON, Canada

E-mail: Susan Watt* - wattms@mcmaster.ca; Wendy Sword - sword@mcmaster.ca; Paul Krueger - krueger@mcmaster.ca; Debbie Sheehan - dsheehan@ city.hamiton.on.ca

*Corresponding author

This article is available from: http://www.biomedcentral.com//47/-2296/3/5

(c) 2002 Watt et al; licensee BioMed Central Ltd. Verbatim copying and redistribution of this article are permitted in any medium for any purpose, provided this notice is preserved along with the article's original URL.

\begin{abstract}
Background: This survey's objective was to provide planning information by examining utilization patterns, health outcomes and costs associated with existing practices in the management of postpartum women and their infants. In particular, this paper looks at a subgroup of women who score $\geq 12$ on the Edinburgh Postnatal Depression Survey (EPDS).
\end{abstract}

Methods: The design is cross-sectional with follow-up at four weeks after postpartum hospital discharge. Five Ontario hospitals, chosen for their varied size, practice characteristics, and geographic location, provided the setting for the study. The subjects were 875 women who had uncomplicated vaginal deliveries of live singleton infants. The main outcome measures were the EPDS, the Duke UNC Functional Social Support Questionnaire and the Health and Social Services Utilization Questionnaire.

Results: EPDS scores of $\geq 12$ were found in 4.3 to $15.2 \%$ of otherwise healthy women. None of these women were being treated for postpartum depression. Best predictors of an EPDS score of $\geq 12$ were lack: of confident support, lack of affective support, household income of $<\$ 20,000$, wanting to stay in hospital longer, identification of learning needs while in hospital, self-identified care needs for an emotional/mental health problem that have not been met and mother's rating of own and baby's health as fair or poor.

Conclusions: Primary care physicians, midwives, and public health nurses need to screen for depression at every opportunity early in the postpartum period. A mother's expression of undue concern about her own or her baby's health may be predictive of postpartum depression. Flexible, mother-focused support from community providers may decrease the prevalence of postpartum depression. 


\section{Background}

By 1998, a hospital stay of 48 hours or less following an uncomplicated, singleton vaginal delivery had become common practice in Ontario. This shortened stay has reduced access to in-hospital identification and treatment of postpartum complications [1]. In response, health care providers, including family physicians, have attempted to provide safe, integrated, cost-effective care for postpartum women and their infants. The objectives of the Ontario Mother and Infant Survey were to provide planning information by examining utilization patterns, health outcomes and costs associated with existing practices in the management of postpartum women and their infants that could be used to further integrate services, and to identify for whom targeted interventions might be beneficial.

One of the difficulties that can follow childbirth is maternal depression. Researchers have reported depression rates in North American women between 8\% and 26\% during the period one month to one year after the birth of a child [1-5]. They found that postpartum depression (PPD) could have a profound impact on the well being of a mother [6], a newborn infant [7-9], and a family in general $[10,11]$.

Research has focused on predisposing characteristics and circumstances of individual women that place them at risk for postnatal depression [12-16]. For example, Beck (1995) identified eight predisposing factors: prenatal depression, maternal history of depression, lack of social support, life stress, child care stress, maternal "blues", marital dissatisfaction, and, prenatal anxiety. A recent meta-analysis identified that postpartum depression is most strongly associated with poor marital adjustment, recent life stressors, and antepartum depression. Other researchers have discussed the difficulties in defining postpartum depression as an entity separate from other types of depression $[17,18]$ and have found wide variations in prevalence using different assessment tools [11,17]. In Ontario, no universal screening protocol is used to detect PPD.

The purpose of this article is to describe the outcomes of a study of the health and social care needs of healthy postpartum women, to alert family physicians to signs of depression in the early postpartum period, and to discuss the impact of reduced lengths of postpartum hospital stay and the introduction of community outreach initiatives on the detection of PPD.

\section{Materials and methods}

The settings for the 1998-99 TOMIS study recruitment were five Ontario hospitals chosen for their varied size, practice characteristics and geographic locations. The design was cross-sectional with follow-up at four weeks after postpartum discharge from hospital. The study recruited 1250 women, 250 from each site, who had vaginally delivered a live, singleton infant who was discharged to the care of, and at the same time as, the mother. Exclusion criteria included women having caesarean sections, multiple births, or major complications for either mother or infants. Maternity floor nurses and/or a site research assistant identified subjects. The study was conducted in seven languages. Ethics approval was obtained from McMaster University, Hamilton, Ontario and each of the five participating hospital sites. The two instruments used, the Mother's Questionnaire and the Mother's Interview Schedule, were developed and tested for reliability and validity during a 1997 pilot project in Hamilton. The mothers answered the questionnaire in hospital, prior to discharge and the interview schedule was administered by telephone, four to six weeks after postpartum discharge, by trained interviewers. Sample size was calculated using 30 subjects per variable [19].

The interview schedule included the Edinburgh Postpartum Depression Scale (EPDS) [20,21] and the Duke UNC Functional Social Support Questionnaire [22]. The EPDS has been used as a screening tool for postpartum depression and a score of $\geq 12$ has been found to be predictive of a diagnosis of postpartum depression [23-26]. Although the EPDS is most often used at 6 weeks postpartum, it has been used antenatally $[38,39]$ and in the early postnatal period (e.g. day 5) [40]. The EPDS was developed as a screening tool, and is not meant to diagnose postpartum depression. A recent review of eighteen EPDS validation studies, suggests that when used in a general population, such as the sample for TOMIS, the positive predictive value may be less than $50 \%$, emphasising the need for further clinical assessment of the women who are identified as having EPDS scores of $\geq 12$ [37]. Two studies have determined that the EPDS, when using $\geq 12$ as a cutoff level, has a sensitivity of $86 \%$ and $68 \%$, a specificity of $78 \%$ and $96 \%$, and a positive predictive value of $73 \%$ and $67 \%$. [20,38]

All service utilization, including hospital, physician, and community care, was collected using the Health and Social Services Utilization Questionnaire [27].

Using t-test, chi-square or Fisher exact tests, we identified potential predictors for postpartum depression. Multiple logistic regression analysis was used to identify the most important predictors. These findings are presented as adjusted odds ratios with corresponding 95\% confidence intervals. The final step in the modelling procedure was to test for the significance of interaction terms, representing possible effect modifiers. The goodness of fit for the final logistic regression model was assessed using the rhosquare statistic [28]. We used SPSS Version 10.0.5 for Win- 
dows, 1999 and Epi-Info Version 6.04c, (1997) for statistical computations and a probability level of $<0.05$ to determine statistical significance.

The study is not predicated on a random sample of all women delivering healthy infants in Ontario. Rather, the study provides five snapshots of groups of women in five locales in Ontario. This geographic diversity is an important consideration if programs and services are purported to be universally available throughout the province. Analysis of the data retains the integrity of each locale and uses location as a variable for understanding differences between groups. A full description of the methodology has been published [29].

\section{Results}

Of the 1,250 women recruited, 875 (70\%) completed the follow-up interview [29]. A profile of women who took part in the interview and their infants is presented in Table 1 . There was no difference in age, parity, or length of stay for those subjects in the study and those who refused to participated or were missed by recruiters. There were no statistically significant differences in the sociodemographic characteristics of interview participants and women and their infants who were lost to follow-up.

Scores of $\geq 12$ on the EPDS were found to range from $4.3 \%$ to $15.2 \%(n=86 / 873)$ of otherwise healthy women in each of the sites. Despite the fact that each of these women had seen a physician in relation to her own or her baby's health, no evidence was found that a health care provider identified maternal depression as a health problem. None of the women reported taking medication normally associated with the treatment of either depression or anxiety, nor did they report seeing a mental health professional, such as a psychiatrist, psychologist, or social worker. No larger percentage of this group had seen a public health nurse or other community care provider than had women scoring $<12$. Therefore, as identified by Wilson $e t$ al., there appears to be an undetected, undiagnosed, and untreated group of clinically depressed early postpartum women in the community who are seeing health providers but not being identified as having a mental health problem [16].

Table I: Profile of Interview Respondents

\begin{tabular}{|c|c|c|c|c|c|}
\hline Characteristic & Site I (\%) n = I 64 & Site $2(\%) n=200$ & Site $3(\%) n=209$ & Site $4(\%) n=137$ & Site $5(\%) n=165$ \\
\hline \multicolumn{6}{|l|}{ Marital status: } \\
\hline Married, common-law, living with partner & 97.6 & 91.0 & 98.6 & 94.2 & 89.1 \\
\hline Single/Widowed/Separated/Divorced & 2.4 & 9.0 & 1.4 & 5.8 & 10.9 \\
\hline \multicolumn{6}{|l|}{ Family income before taxes: } \\
\hline$<\$ 20,000$ & 13.7 & 18.8 & 6.5 & 20.0 & 20.4 \\
\hline$\$ 20,000$ to $\$ 39,999$ & 15.7 & 25.5 & 9.9 & 19.4 & 24.5 \\
\hline$\$ 40,000$ to $\$ 59,999$ & 14.4 & 29.7 & 26.9 & 22.5 & 23.1 \\
\hline$\$ 60,000$ to $\$ 79,999$ & 19.0 & 14.1 & 26.9 & 20.9 & 18.4 \\
\hline$\$ 80,000+$ & 37.3 & 12.0 & 29.9 & 17.1 & 13.6 \\
\hline \multicolumn{6}{|l|}{ Cultural group identity (self identified): } \\
\hline Canadian & 37.8 & 90.0 & 84.7 & 35.0 & 90.3 \\
\hline Other than Canadian & 62.2 & 10.0 & 15.3 & 65.0 & 9.7 \\
\hline \multicolumn{6}{|l|}{ Language spoken most often at home: } \\
\hline English & 61.6 & 97.0 & 97.6 & 71.5 & 86.7 \\
\hline Other than English & 38.4 & 3.0 & 2.4 & 28.5 & 13.3 \\
\hline \multicolumn{6}{|l|}{ Highest level of education: } \\
\hline Less than high school & 6.1 & 13.5 & 3.8 & 9.5 & 10.4 \\
\hline Completed high school & 12.2 & 14.0 & 14.4 & 19.0 & 9.8 \\
\hline Community college or technical school & 28.0 & 48.0 & 38.8 & 35.0 & 48.8 \\
\hline University (part or complete) & 40.9 & 18.5 & 31.1 & 19.7 & 25.6 \\
\hline Graduate degree & 12.8 & 6.0 & 12.0 & 9.5 & 5.5 \\
\hline \multicolumn{6}{|l|}{ Mother's age: (years) } \\
\hline Mean & 32.5 & 29.4 & 30.7 & 30.3 & 28.2 \\
\hline Min/Max & $17 / 43$ & $17 / 43$ & $19 / 40$ & $|6 / 4|$ & $18 / 42$ \\
\hline \multicolumn{6}{|l|}{ Baby's birth weight: (grams) } \\
\hline Mean & 3431 & 3666 & 3551 & 3480 & 3530 \\
\hline \multicolumn{6}{|l|}{ Gestation: (weeks) } \\
\hline Mean & 39.5 & 40.0 & 39.8 & 39.5 & 39.6 \\
\hline
\end{tabular}


In order to identify the best predictors of PPD we first conducted univariate analyses of all variables hypothesized a priori to be associated with PPD (hospital site was a variable we hypothesized could be associated with PPD). In fact, we did find that the site of recruitment was associated with PPD. In order to identify the most important predictors of PPD (and simultaneously adjust for other important predictors) we conducted a logistic regression analysis. Site was not an important predictor of PPD, given the other variables we examined. In fact, forcing site into the final logistic regression model (i.e, adjusting for site) did not have any effect on the size of the odds ratios (i.e, was not a confounding factor). As such, site was neither a confounder nor did it significantly improve the fit of the model. Thus, other variable's were examined in an effort to find more predictive variables and to understand the wide variability in the found rates of depression among the sites.

The univariate analyses revealed 55 variables that were statistically associated with an EPDS score of $\geq 12$. Social and health characteristics of the mother (e.g., age, presence of chronic health problems), characteristics of their social environment (e.g., cultural background, language spoken at home, confident support [30], and their care experiences (e.g., use of paediatrician, readiness for discharge, unmet learning needs) were among the significant associated variables. There was a significant correlation between these scores and maternal endorsement of an unmet need for help with a mental health problem or an emotional difficulty and with a self-rating of their own general health as "fair" to "poor".

Only variables that had a statistically significant association with PPD were included in the logistic regression analysis. A forward, likelihood-ratio method was used for the logistic regression modelling. In order to be included, variables had to either significantly improve the fit of the model ( $p \leq 0.05)$ or be confounding factors. The logistic regression analysis produced odds ratios that have been simultaneously adjusted for all other variables in the final model. The goodness of fit of the logistic regression models was assessed using the rho-squared statistic [18]. A rho-square value between 0.20 and 0.40 suggests a very good fit of the model.

When entered into a logistic regression, eight factors were determined to provide the best predictors of an EPDS score of $\geq 12$ for this group: lack of confidant support (i.e., social relationships in which participants can share thoughts, experiences, and ideas), lack of affective support (i.e., social relationships in which individuals provide positive emotional support for each other), household income of $<\$ 20,000$, wanting to stay in hospital longer, identification of learning needs while in hospital, self- identified unmet need for care for an emotional/mental health problem, mother's rating of her own health as fair or poor, and mother's rating of the health of her baby as fair or poor (See Table 2). Length of post delivery hospital stay, initiation or continuation of breastfeeding, and the amount or type of health and social service utilization, although identified in the literature as predictive factors, were not associated with EPDS scores.

\section{Discussion}

Health care providers have long been concerned with identifying and treating depression in new mothers but it has been difficult to predict which women are most at risk. This difficulty has been exacerbated by shorter hospital stays, a initial focus on infant rather than maternal health, and practice patterns that splinter the care of mothers and newborns among a variety of health professionals.

While the literature often provides conflicting evidence about the etiology and prevalence of this phenomenon [31], the clinician is faced with a woman who is in distress, who is often not able to identify the nature or source of the difficulty, and who is looking to the primary care provider for help. Whether one views the etiology of this distress from a biomedical or sociological perspective, the problem of early identification and intervention remains. Failure to diagnosis and treat PPD may result in the inability of a mother to provide adequate infant care [32] and increase the risk for infant cognitive and emotional delay [33].

None of the mothers in this study who score $\geq 12$ on the EPDS reported being diagnosed with or treated for depression. None reported seeing a mental health specialist and none were taking antidepressant drugs, a finding similar to a previous study [34]. Despite the predictive value of self-identified emotional or mental health issues in relation to early postpartum depression [35], only $22.2 \%$ to $30.8 \%$ of women in this study with EPDS of $\geq 12$ reported that they had experienced an emotional or mental health problem since discharge from hospital. However, $44.4 \%$ to $52.0 \%$ identified the need for reassurance and support.

The EPDS was developed as a screening tool, and is not meant to diagnose actual postpartum depression. A recent review of eighteen EPDS validation studies, suggests that when used in a general population such as the sample for TOMIS, the positive predictive value may be less than $50 \%$, emphasizing the need for further clinical assessment of the women who are identified as $\geq 12$ [40]. The TOMIS results also suggest that prenatal distress, while important, is an insufficient predictor of postpartum depression $[37,38]$. Given that this group of distressed mothers rarely identified themselves as having received help for a prena- 


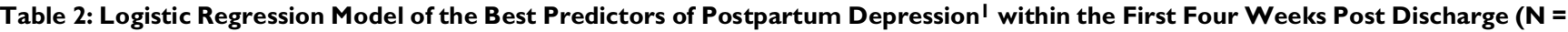
$870^{2}$ )

\begin{tabular}{|c|c|c|}
\hline Predictors of Postpartum Depression ${ }^{3}$ & Adjusted Odds Ratio ${ }^{4}$ & 95\% Confidence Ir \\
\hline \multicolumn{3}{|l|}{ Confidant support score 5,5 : } \\
\hline 20 to 25 & 1.00 & - \\
\hline 5 to 19 & 2.28 & $(1.33,3.93)$ \\
\hline \multicolumn{3}{|l|}{ Mother's self rating of health ${ }^{6}$ : } \\
\hline Excellent/very good & 1.00 & - \\
\hline Good/fair/poor & 2.84 & $(1.70,4.74)$ \\
\hline \multicolumn{3}{|l|}{ Affective support score 5,6 : } \\
\hline 15 & 1.00 & - \\
\hline 3 to 14 & 2.26 & $(1.31,3.91)$ \\
\hline \multicolumn{3}{|l|}{ Total household income before taxes and deductions ${ }^{7}$ : } \\
\hline$\$ 20,000$ or more & 1.00 & - \\
\hline Less than $\$ 20,000$ & 2.45 & $(1.37,4.36)$ \\
\hline \multicolumn{3}{|c|}{ After infant was born, mother wanted to stay in hospital 6 : } \\
\hline Shorter/just right/not sure & 1.00 & - \\
\hline Longer & 1.79 & $(1.04,3.09)$ \\
\hline \multicolumn{3}{|c|}{ Help needed to care for an emotional $/$ mental health problem 6 : } \\
\hline Not needed/able to get care or help if needed & 1.00 & - \\
\hline Care or help needed but unable to get & 3.10 & $(1.14,8.44)$ \\
\hline \multicolumn{3}{|l|}{ Mother's rating of infant's health ${ }^{6}:$} \\
\hline Excellent/very good/good & 1.00 & - \\
\hline Fair/poor & 3.24 & $(1.15,9.18)$ \\
\hline \multicolumn{3}{|l|}{ Learning needs while in hospital 6,8 : } \\
\hline 0 to 5 & 1.00 & - \\
\hline 6 or more & 1.77 & $(1.04,3.02)$ \\
\hline
\end{tabular}

Final Logistic Regression Model Statistics: Rho-square $=0.21$ (a pseudo $R^{2}$, values between 0.2 and 0.4 suggest a very good fit) Hosmer and Lemeshow Goodness-of-fit test $=0.91$ (values greater than 0.25 indicate good fit) $91.0 \%$ correctly classified 'Edinburgh Postnatal Depression Scale ${ }^{2}$ Five mothers had missing values for one or more of the variables included in the final model ${ }^{3}$ Exact questions may be obtained from the corresponding author ${ }^{3}$ Odds ratios for categorical variables represent comparisons with the referent group $(O R=1.00)$ after adjustment for all other variables in the model ${ }^{4}$ From The Duke-UNC Functional Social Support Questionnaire. ${ }^{5}$ Information collected from mother four weeks after discharge from hospital 6 Information collected from mother prior to discharge from hospital ${ }^{7}$ Learning needs included information on hospital routines, breast feeding, bottle feeding, infant care and behaviour, signs of illness in infant, physical changes and care of self, emotional changes for self, sexual changes and intercourse, family changes, community support services and other

tal mental health problem, and not all of the mothers who identified prenatal mental health problems had scores of $\geq 12$ at four weeks post discharge, it is not adequate for primary care providers to assume that a woman's prepregnancy or prenatal mental health status is predictive of postnatal depression [39].

Perhaps women have normalized the symptoms that professionals associate with depression. While women who identified a need for reassurance and support were, in the main, able to get it, women who identified a need for help with an emotional or mental health problem reported much less success in obtaining assistance. It is unclear how the women themselves differentiated between these two needs but it was evident that somehow they discriminated between common social support needs and the need for help with what they had defined as a mental health issue.
All participants had contact with a physician since their discharge from hospital. All identified contact in relation to their infant's health, but less than $10 \%$ of women in any of the sites identified that this contact had been for their own needs.

Mothers who scored $\geq 12$ identified their own health and the health of their newborn infant as less than optimal. This evaluation was in contrast to mothers who scored less than 12, who evaluated both as "good to excellent". Hospital readmission of either mother or infant was not found to be a related to $\geq 12$ scores.

Given that mothers with scores of $\geq 12$ reported low levels of both confident and affective support, these results lend credibility to the notion that early postpartum depression may be an expression of a woman's sense of being overwhelmed by a major life-changing event. Thrust into the care of a newborn infant, without strong support, mothers may be primed for an emotional response that they iden- 
tify in a negative way. "Anxiety", "depression", or "stress" may be used to describe the set of responses, but this research shows these women are experiencing significant distress and may be at risk for more serious, long-term difficulties $[12,33,37,38]$. These finding are consistent with other studies that have identified worries about ones own health or about an infant's health, and lack of social support as predictors of PPD [44,45].

Although a woman's sense of personal readiness for discharge was not one of the most strongly associated variables with $\geq 12$ EPDS scores, it was an important predictor and may be a clue to providers in identifying an "at risk" group while they are still in hospital. It is important to recognize that the message from these mothers was not "I want to stay in hospital" as much as "I don't think I can manage at home". Given that most women $(60.0 \%$ to $76.9 \%$ ) said at the time of discharge that they thought they were ready for discharge, women who want to stay in hospital for a longer period need particular attention. We need to understand their reasons for believing that an increased length of stay would be helpful. Does the woman want to stay longer because she is afraid that she or her infant is "sick"? Is the hospital a "safe haven"? What resources-personal, financial, social - would make discharge feel "safer"? What role could primary care providers in the community play in easing the transition home?

A recently published UK study [46] found that enhanced and flexible community care for postpartum women that focused on the individual needs of each woman. Home visits during the first 4 weeks after the baby's birth were scheduled according to the needs of the mother. Four months after deliver the mother who received this enhanced care were found to be equally physically health and in better mental health than those who received only standard midwifery care. Mothers receiving enhance care reported a significantly different appreciation of the relationship with their midwife that suggests that both affective and confidant support, notably absent in the group of women in our study who scored $\geq 12$ on the EPDS was achieved through the provision of these services.

Simple inquiries by care providers about a woman's sense of her own readiness for discharge might alert them to potential distress [27]. At four weeks post-discharge, only $44.0 \%$ to $72.0 \%$ of women at each site thought that their stay had been the appropriate length for them - significantly fewer than at the time of discharge. Policy changes introduced in Ontario after this research was completed provide a choice of a 60-hour stay at the discretion of the mother. Women exercising this option may represent a group at higher risk for depression in the postpartum period. It is unclear if extended hospitalization reduces the risk for PPD. However, it is reasonable to assume that dis- charging a distressed woman into a community without guaranteeing adequate assistance is a certain prescription for increased risk.

\section{Conclusions}

Our results suggest that if women express undue concern about their own health, or the health of their infants, it might be wise for health care providers to explore the possibility of maternal depression. It is not clear if mothers would volunteer this concern or would only evaluate their own health and that of their infant in negative terms if asked. Frequent unscheduled contact with providers by telephone or visits may signal this heightened concern.

The ideal time frame for screening for PPD has not yet been established. Family physicians need to recognize that despite recent policy changes that offer all consenting women a telephone call from a public health nurse within 48 hours of hospital discharge and a possible home visit, these contacts may be too early or too "baby-focused" to identify women at risk for PPD.

Family physicians, midwives, and public health nurses have an important role to play not only in ensuring the physical well being of newborns and women in the postpartum period, but also in early detection of PPD. Well baby follow up appointments occur much earlier than the standard six-week post delivery check up. For at least some women, screening for PPD as part of well baby follow up may afford an earlier opportunity for prompt and effective interventions including additional social support and targeted learning opportunities in the woman's own community that have been shown to be helpful to a significant number of women in reducing the incidence of PPD.

\section{List of abbreviations \\ PPDPost Partum Depression}

\section{TOMISThe Ontario Mother and Infant Survey}

EPDSEdinburgh Postnatal Depression Scale

SPSSStatistical Package for the Social Sciences

\section{Declaration of Competing interests}

None declared.

\section{Acknowledegments}

This study was funded by the Canadian Health Services Research Foundation and co-sponsored by: Social and Public Health Services Department, City of Hamilton, Public Health Research, Education and Development Program; the System-Linked Research Unit on Health and Social Service Utilization, McMaster University; and St. Joseph's Health Care System Research Network.

Other investigators on the TOMIS project are A. Gafni, K. Soon-Lee, and J. Roberts of McMaster University. 


\section{References}

I. Sword W, Watt S, Krueger P, Sheehan D, Lee KS, Roberts J, Gafni A: New mothers identify information needs:ations for postpartum community care providers. Public Health and Epidemiology Report Ontario 2000, I I:38-44

2. Cox JL, Murray D, Chapman G: A controlled study of the onset, duration, and prevalence of postnatal depression. Br J Psychiatry 1993, 163:27-31

3. Gotlib IH, Whiffen VE, Mount JH, Milne K, Cordy NI: Prevalence rates and demographic characteristics associated with depression in pregnancy and the postpartum. J Counsel Clin Psychol 1989, 57:269-274

4. O'Hara MW, Zekoski EM, Philips LH, Wright Ej: Controlled prospective study of mood disorders: comparison of childbearing and nonchildbearing women. J Abnorm Psychol 1990, 99:3- I5

5. Warner R, Appleby L, Whitton A, Faragher B: Demographic and obstetric risk factors for postnatal psychiatric morbidity. $\mathrm{Br} J$ Psychiatry 1996, I 68:607-6II

6. Beck CT: Teetering on the edge: A substantive theory of postpartum depression. Nurs Res 1993, 42:42-48

7. Beck CT: The effects of postpartum depression on maternalinfant interaction: A meta-analysis. Nurs Res 1995, 44:298-304

8. Campbell SB, Cohn JF, Flanagan C, Popper S, et al: Course and correlates of postpartum depression during the transition to parenthood. Dev Psychopath 1992, 4:29-47

9. Holden JM: Postnatal depression: Its nature, effects, and identification using the Edinburgh Postnatal Depression Scale. BIRTH 1991, 18:211-221

10. Murray J: The impact of postnatal depression on infant development. J Child Psychol Psychiatr 1992, 33:543-56 I

II. Stein A, Gath D, Bucher J, Bond A, Day A: The relationship between post-natal depression and mother-child interactions. Br J Psychiatry 1992, I 58:46-52

12. Llewellyn AM, Stowe ZN, Nemeroff CB: Depression during pregnancy and the puerperium. J Clin Psychol 1997, 58(suppl):26-32

13. Righetti-Veltema M, Conne-Perreard E, Bousquet A, Manzano J: Risk factors and predictive signs of postpartum depression. J Affect Disord 1998, 49: 167-180

14. Viinãmaki H, Niskanen L, Pesonen P, Saarikoski S: Evolution of postpartum mental health. J Psychoso. Obstet. Gynecol 1997, 1 8:213-219

15. Beck CT: A checklist to identify women at risk for developing postpartum depression JOGNN 1998, 27:39-46

16. Wilson LM, Reid AJ, Midmer DK, Biringer A, Carroll JC, Stewart DE: Antenatal psychosocial risk factors associated with adverse postpartum family outcomes. Can Med Assoc J 1996, I 54:785799

17. Whiffen VE: The comparison of postpartum with non-postpartum depression: A rose by any other name? J Psychiatr Neurosci 1991, 16:160-65

18. Whiffen V: Is postpartum depression a distinct diagnosis? Clin Psychol Rev 1992, 12:485-508

19. Burns N, Groves S: The Practice of Nursing Research: Conduct, Critique and Utilization. 1997

20. Cox JL, Holden JM, Sagovsky R: Detection of postnatal depression: development of the 10-item Edinburgh Postnatal Depression Scale. Br J Psychiatry 1987, I 50:782-786

21. Murray D, Cox JL: Screening for depression during pregnancy with the Edinburgh Depression Scale (EPDS). J Repro Infant Psychol. Special Issue: psychiatric disorders associated with childbearing 1990, 8:99-107

22. Broadhead WE, Gehlbach SH, deGruy FV, Kaplan BH: The DukeUNC functional social support questionnaire measurement of social support in family medicine patients. Med Care 1998, 26:709-723

23. Georgiopoulos A, Bryan T, Wollan P, Yawn B: Routine screening for postpartum depression. Journal of Family Practice 200 I, 50: I I7122

24. Evins GG, Theofrastous JP, Galvin SL: Postpartum depression: A comparison of screening and routine clinical evaluation. $\mathrm{Am} J$ Obstet Gynaecol 2000, I 82: 1080-1082

25. Bågedahl-Strindlund $M$, Borjessoon K: Postnatal depression: a hidden illness. Acta Psychiatrica 1998, 98:272-275

26. Thompson WM, Lazarus HB, Richards C: A comparison of the performance of rating scales used in the diagnosis of postnatal depression. Acta Psychiatrica 1998, 98:224-227
27. Roberts J, Sword W, Watt S, Gafni A, Krueger P, Sheehan D, SoonLee $\mathrm{K}$ : Costs of postpartum care: Examining associations from the Ontario mother and infant survey. Can J Nus Res. 200I, 33:19-34

28. Wrigley N: Categorical data analysis for geographers and environmental scientists. New York: Longman I 985, 49-62

29. Sword WA, Watt S, Krueger PD, Soon-Lee K, Sheehan DD, Roberts J, Gafni A: Understanding newborn infant readmission: findings of the ontario mother and infant survey. Can J Public Health 200I, 92:196-200

30. Broadhead E, Gehlbach S, DeGruy F, Kaplan B: Functional versus structural social support and health care utilization in a family medicine outpatient practice. Med Care 1989, 27:221-233

31. Wood AF, Thomas SP, Droppleman PG, Meighan M: The downward spiral of post partumdepression. MCN Am J Matern Child Nurs 1997, 22(6):308-16

32. Stuart S, Couser G, Schilder K, Ohara MW, Gorman L: Postpartum anxiety and depression: Onset and comorbidity in a community sample. J Nerv Ment Dis 1998, I 86:420-4

33. Cooper PJ, Murray L: Effects of postnatal depression in infant development. Arch Dis Child 1997, 77(2):99-101

34. Mclntosh J: Postpartum depression: Women's help-seeking behaviour and perceptions of cause. J Adv Nur 1993, I 8: | 78- I 84

35. Dejoseph JF: A feminist analysis of depression during the childbearing year. Issues Ment Heal Nurs, Special Issue: Thoughtful feminism in mental health nursing 1997, I 8:5 I I-522

36. Appleby L, Gregoire A, Platz C, Prince M, Kumar R: Screening women for high risk depression. J Psychosom Res 1994, 38:539545

37. Kelly A, Deakin B: Postnatal depression and antenatal morbidity. Br I Psychiatry 1992, I 6 I:577-578

38. Evans J, Heron J, Francomb H, Oke S, Golding J: Cohort study of depressed mood during pregnancy and after childbirth. BM] 200I, 323(7307):257-60

39. O'Connor TG, Hawkins N, Dunn J, Thorpe K, Golding J, et al: Family type and depression in pregnancy: Factors mediating risk in a community sample. J Marriage Family 1998, 60:757-770

40. Eberhard-Gran M, Eskild A, Tambs K, Opjordsmoen S, Samuelsen SO: Review of validation studies of the Edinburgh Postnatal Depression Scale. Acta Psychiatr Scand 200 I, I 04(4):243-9

4I. Josefsson A, Berg G, Nordin C, Sydsjo G: Prevalence of depressive symptoms in late pregnancy and postpartum. Acta Obstet Gynecol Scand. 200 I, 80(3):25I-5

42. Luoma I, Tamminen T, Kaukonen P, Laippala P, Puura K, Salmelin R, Almqvist F: Cohort study of depressed mood during pregnancy and after childbirth. J Am Acad Child Adolesc Psychiatry 200 I, 40(12): | 367-74

43. Bergant AM, Heim K, Ulmer H, Illmensee K: Prenatal screening: Longitudinal study of maternal depressive symptoms and child well-being. J Psychosom Res 1999, 46(4):391-4

44. Seguin L, Potvin L, St Denis M, Loiselle J: Socio-economic factors and postnatal depressive symptomatology: A longitudinal study. Women and Health 1999, 29(I):57-71

45. Wickburg B, Hwang CP: Screening for postnatal depression in a population-based Swedish sample. Acta Psychiatr Scand 1997, 94:62-6

46. MacArthur C, Winter HR, Bick DE, Knowles H, Lilford R, Henderson C, Lancashire RJ, Braunholtz DA, Gee H: Effects of redesigned community postnatal care on womens' health 4 months after birth: a cluster randomized controlled trial. Lancet 2002, 359:378-855

\section{Pre-publication history}

The pre-publication history for this paper can be accessed here:

http://www.biomedcentral.com/1471-2296/3/5/prepub 